$\begin{gathered}\text { Revista do Departamento de Geografia } \\ \text { Universidade de São Paulo } \\ \text { www.revistas.usp.br/rdg } \\ \text { Volume Especial (2016) }\end{gathered}$
ISSN 2236-2878

\title{
EXTREMOS DE TEMPERATURA DO AR EM BELO HORIZONTE: VARIABILIDADE NATURAL E INFLUÊNCIA DO CLIMA URBANO
}

\author{
AIR TEMPERATURE EXTREMES IN BELO HORIZONTE: \\ VARIABILITY NATURAL AND INFLUENCE OF URBAN CLIMATE
}

\author{
Carlos Henrique Jardim \\ Universidade Federal de Minas Gerais \\ dxhenrique@gmail.com \\ Marina Rozendo Silva \\ Universidade Federal de Minas Gerais \\ marinarozendo@yahoo.com.br
}

\begin{abstract}
Changes in land use and occupation introduced into the environment (agriculture and urbanization, mostly) change the energy balance, interfering with variations of climatic elements. In order to check the temporal dimension of these changes in climate, the maximum and minimum temperature data were analyzed in the cities of Belo Horizonte and Ibirite (Minas Gerais, Brazil), for the period 1961-2014. The analysis procedures included using descriptive statistics and trend analysis and correlation and microclimate analysis techniques and urban climate. The results indicated natural tendency to increase in the maximum and minimum temperature and evidence of human influence on the temporal variation of this climatic element.
\end{abstract}

Keywords: Land use, Air temperature, Trend analysis, Urban climate.
Palavras-chave: Uso da terra, Temperatura do ar, Análise de tendência, Clima urbano. 


\section{INTRODUÇÃO}

Atualmente, perante o alarmismo criado ao redor de questões sobre mudanças climáticas, muitas pessoas, desde profissionais especializados ao cidadão comum, são encorajadas a emitir opiniões a respeito do clima, mesmo aqueles que não têm contato com quaisquer informações básicas dessa área e muito menos envolvimento com pesquisas sobre o tema. Outros temas complexos como meio ambiente, educação escolar e políticas públicas são alvos igualmente frequentes de pseudo-análises científicas. O que acontece é que muitas dessas considerações não passam de meras suposições e/ou são apoiadas puramente no senso-comum. Quantas dessas pessoas, supostamente interessadas, já se depararam com séries temporais de dados meteorológicos e/ou oriundos de trabalho de campo? E mesmo que isso acontecesse, quantos destes saberiam extrair algum significado desses dados e transformá-los em informação? Até para quem lida diretamente com esse tipo de fonte constitui-se tarefa difícil caracterizar a influência do clima sobre a multiplicidade de organizações espaciais terrestres (sistemas ambientais) e separar o que resulta de interações entre fatores naturais daqueles ligados à ação antrópica.

Exemplo recente desse tipo de distorção ocorreu em Belo Horizonte, durante os meses de outubro e novembro de 2012 e 2015, quando a cidade foi acometida por sequencias de dias muito quentes com temperaturas superiores a $35,0^{\circ} \mathrm{C}$. Houve, inclusive, aqueles que se apressaram em afirmar, sem qualquer tipo de cautela, que tal valor nunca havia sido registrado na cidade, aludindo profundas transformações no sistema climático global.

Ao estudar o clima de um dado espaço terrestre, não se pode atribuir a um único fator a responsabilidade pela sua organização. Normalmente há vários fatores envolvidos: latitude, altitude, influência oceânica, topografia, uso da terra etc. Isso se deve ao fato do clima ser um sistema complexo e, portanto, instável e dinâmico, no qual múltiplos componentes e propriedades em constante modificação se inter-relacionam para produzir um quadro final (impacto) diferente do original. A necessária inserção do objeto de estudo geográfico-climatológico numa estrutura hierárquica (níveis escalares) aumenta a complexidade do objeto.

Além dessa necessidade em se precisar o impacto da ação humana sobre o ambiente, cabe salientar que o clima encerra nele mesmo importantes desvios na variação de seus elementos (temperatura, umidade, chuvas, ventos etc.), motivados por fatores estáticos e dinâmicos como a topografia, altitude, latitude, uso da terra, atividade solar, correntes oceânicas, massas de ar etc., o que torna impossível (perante a tecnologia atual) a previsão de suas condições a médio e longo prazo com elevado grau de confiabilidade.

Diferenças de temperatura do ar entre os diversos bairros numa mesma cidade, enchentes e alagamentos, diminuição das fontes de umidade para o ar, poluição atmosférica etc. comparecem entre alguns dos diferentes tipos de impactos decorrentes das modificações realizadas pelas sociedades humanas ao longo do tempo. A ampliação do debate ao redor da influência das cidades no clima é importante, considerando que as cidades incluem-se entre os espaços preferenciais de habitação humana nas diferentes partes do mundo. Entretanto, é importante, também, que se defina a intensidade e o alcance dessas transformações introduzidas no espaço em relação ao ambiente maior no qual se insere, a fim de que se produzam prognósticos melhor ajustados às características dos fenômenos identificados.

Nesse sentido, o objetivo deste artigo é investigar a participação dos fatores naturais e antrópicos na ocorrência e intensidade de valores extremos de temperatura do ar na cidade de Belo Horizonte. Há evidências de que o acúmulo de transformações introduzidas no espaço pela atividade humana (multiplicação de fontes de radiação térmica de origem antropogênica), paralelo às variações induzidas por fatores naturais, acrescentou variações adicionais aos elementos atmosféricos e, portanto, no ritmo climático local e urbano de Belo Horizonte, que, por sua vez, constitui-se em indicador negativo de qualidade ambiental considerando o saldo energético anual positivo para essa faixa de latitude.

Os dados utilizados foram obtidos em campanhas de campo entre os anos de 2012 e 2013 e do exame de séries temporais de dados oriundos de estações meteorológicas do Instituto Nacional de Meteorologia (INMET) em Belo Horizonte e localidade vizinha (município de Ibirité) no período compreendido entre 1961 e 2015.

A importância dessa discussão reside no fato de que uma vez identificada as causas do desencadeamento de um dado evento ou fenômeno, medidas poderão ser propostas visando formas de organização do espaço compatíveis com as características do ambiente. 


\section{PROCEDIMENTOS METODOLÓGICOS}

As fontes de dados utilizadas incluíram material bibliográfico diverso (livros, artigos, dissertações, teses, conteúdo veiculado pela internet etc.), consulta a bancos de dados meteorológicos (séries históricas) do Instituto Nacional de Meteorologia-INMET (www.inmet.gov.br) e trabalho de campo.

A série principal de dados utilizada consta dos registros da estação meteorológica convencional situada na Av. do Contorno com a Av. Raja Gabaglia, na área central da cidade de Belo Horizonte $\left(19,93^{\circ} \mathrm{S}\right.$ e

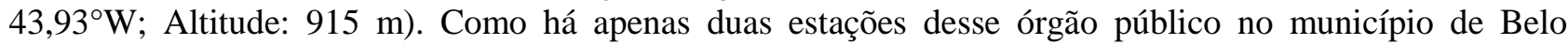
Horizonte, a escolha dessa estação em especial deveu-se a sua relativa antiguidade e localização no centro da cidade, o que possibilitou (supostamente) acompanhar a evolução das mudanças introduzidas no ambiente pela ampliação da área urbana e sua influência nas variações dos elementos do clima.

Para efeitos comparativos com os dados de Belo Horizonte utilizou-se de dados da estação de Ibirité (20,01 $\mathrm{S} ; 44,05 \mathrm{~W}$; Altitude: $814,54 \mathrm{~m})$, situada ao sul deste município em área abrangida pela unidade de conservação do Pq. Estadual do Rola Moça.

A análise dos dados meteorológicos foi dividida em três etapas a partir de um esquema de decomposição temporal-cronológica, iniciando pela série de dados de longo prazo até os dados obtidos em campo: (1) seleção dos valores extremos de temperatura ao longo da série temporal; (2) seleção de dados para análise de correlação, a partir da técnica estatística de análise de regressão linear simples para verificar tendências positivas ou negativas e possíveis correlações entre crescimento urbano e variação temporal da temperatura do ar; (3) seleção e análise de sequencias temporais diferenciadas temporalmente, sendo uma delas do período de 1961-1970 e a outra, mais recente, para o período de 2000-2010, cujos valores foram agrupados por dia da semana, a fim de verificar mudanças no ritmo diário/semanal de variação da temperatura do ar ao longo do tempo e possível relação com mudanças introduzidas na organização das funções e dinâmica urbanas; (4) análise de dados obtidos diretamente em campo a partir de tomadas simultâneas, em condições micro e topoclimáticas diferenciadas, distribuídas pelos municípios de Belo Horizonte, Nova Lima, Contagem e Betim.

Com relação ao item 03 , hipoteticamente considerando, o segmento temporal mais antigo representaria um espaço urbano com menor grau de transformação, ou "derivação" como coloca Monteiro (1975), e o segmento mais recente seria representativo de um espaço urbano resultado de maior acúmulo de transformações (relação mais estreita com os climas urbanos atuais), cujo reflexo transpareceria na variação dos atributos. E, a fim de constatar isso, os valores médios de temperatura do ar foram agrupados e ordenados de acordo com os dias da semana, ou seja, calcularam-se as médias para cada dia da semana, dispostos posteriormente na forma de gráficos para comparação e análise.

Posteriormente, os resultados obtidos para Belo Horizonte (itens 02 e 03) foram comparados aos do município de Ibirité (tomada como referencial de cidade de pequeno porte) que, ao longo do tempo, não experimentou o mesmo grau de transformação espacial em relação a Belo Horizonte (crescimento da área urbana, frota de veículos, número de habitantes, diversificação do parque industrial e de serviços etc.).

Procedimento semelhante de análise foi utilizado por Azevedo (2001a; 2001b) em estudo diagnóstico na cidade de São Paulo e justifica-se na medida em que o propósito era avaliar a participação de fatores antropogênicos nas variações dos atributos climáticos e imposição de um ritmo urbano à variação dos elementos climáticos, cuja organização guarda estreita relação com o ritmo semanal de deslocamentos da população até os postos de trabalho, lazer, férias etc., reflexo dos movimentos internos na cidade.

Paralela à análise das séries temporais, foram analisados dados obtidos em campo, referentes a mensurações da temperatura do ar no período de 22/12/2012 a 21/03/2013 (90 dias), de forma contínua e simultânea, em intervalos de sessenta minutos, utilizando-se de registradores automáticos tipo dataloggers (modelo Icel HT 500) acondicionados em abrigos meteorológicos projetados para essa finalidade, distribuídos entre 08 pontos em localidades com diferentes características de relevo e uso da terra, entre os municípios de Belo Horizonte, Contagem, Betim e Nova Lima (Minas Gerais - Brasil). Para efeito de análise, considerando as diferenças entre os postos, foram utilizados apenas os dados dos postos do Barreiro em área periurbana, ao sul de Belo Horizonte, e da área urbana de Contagem, próxima ao centro industrial. Os registradores foram aferidos com a estação meteorológica da rede oficial do INMET Belo Horizonte Pampulha.

Os dados de campo foram analisados de forma comparativa, selecionando-se, inicialmente, os postos mais representativos de ambiente urbano (na área urbana de Contagem) e periurbana da regional Barreiro no sul de Belo Horizonte. A frequência (\%) dos maiores e menores valores de temperatura, verificada de forma 
comparativa entre os valores obtidos em cada um dos postos, serviu de base para avaliar as condições propícias à estruturação e recorrência de condições ligadas aos climas urbanos.

Consideraram-se, também, as condições atmosféricas regionais, definidas pela frequência e sucessão dos sistemas atmosféricos, cuja participação foi determinada através da análise de imagens de satélite e cartas sinóticas e as características ambientais de cada posto (altitude, topografia, uso da terra etc.).

\section{REVISÃO TEÓRICA}

É fato que as cidades impõem modificações às propriedades do ar com o qual se encontra em contato, demonstrado pelas variações dos principais atributos atmosféricos em uma série de pesquisas sobre o assunto, datando as primeiras referências no século 19 oriunda do Reino Unido e incrementado contínua e sucessivamente a partir de meados do século 20. No Brasil as primeiras referências datam da década de 1970.

Essa transformação nas propriedades da atmosfera, entretanto, se traduz em inúmeras situações, desde aquelas marcadas por alertas em relação à segurança do cidadão (risco de inundação, situações críticas de qualidade do ar, baixos índices de umidade relativa, desconforto térmico etc.) até aquelas nas quais os efeitos do clima urbano praticamente desaparecem. Isso se deve às características singulares de cada localidade em relação às características dos fatores urbanos (porte e funções da cidade, número de habitantes, frota de veículos etc.) e naturais (relevo, vegetação etc.) em interação com a dinâmica atmosférica local e regional.

A diversidade de situações propícias ou não à organização dos climas urbanos produziu uma diversidade de pesquisas cuja quantidade de trabalhos e, consequentemente, de metodologias empregadas, extrapolam a capacidade de uma revisão completa acerca do assunto neste artigo. Sendo assim foram considerados apenas alguns trabalhos em diferentes linhas de investigação sobre as variações de temperatura em áreas urbanas.

Dentre os trabalhos que abordam o aspecto metodológico destacam-se as obras de Monteiro (1971; 1975; 1978) diretamente ligados ao escopo deste artigo. São eles, respectivamente, "Análise rítmica em climatologia", "Teoria e clima urbano" e "Derivações antropogênicas dos geossistemas terrestres no Brasil e alterações climáticas".

$\mathrm{Na}$ linha do primeiro trabalho (MONTEIRO, 1971, p.4) o ritmo é definido como "expressão da sucessão dos estados atmosféricos". Definição esta que praticamente se sobrepõe a definição de clima dada por Sorre (1934). A "análise rítmica" seria, nesse sentido, uma tentativa de integração das escalas espaciais e temporais: a gênese (ou origem) do evento estaria no nível regional (mesoescala), associada à dinâmica das massas de ar e o clima local (microescala) seria a resposta em superfície frente à modulação imposta pelo relevo à dinâmica das massas de ar. Os espaços menores no interior dos climas locais (mesoclimas, topoclimas e microclimas) responderiam por formas particularizadas em microescala, produto de interações do ar com os variados e particulares aspectos da paisagem (incluindo a multiplicidade de componentes e dinâmicas antrópicas).

A ênfase dada ao conceito de "escala" enquanto sinônimo de hierarquia, conduz implicitamente à ideia de níveis de organização e, consequentemente, de sistema climático (escala $\rightarrow$ hierarquia $\rightarrow$ níveis de organização $\rightarrow$ sistema) conforme abordado por Jardim (2007). Portanto, não se trata de definir o clima como um componente de um sistema, quando, na verdade, trata-se de um sistema maior que governa a ação dos demais sistemas.

Uma vez que o clima se reveste de interações geográficas identificadas pelos "desvios" nas variações dos elementos atmosféricos através da "necessidade de considerar a realidade dos extremos em confronto com as abstrações médias" (Idem, p.2) e a repercussão (impacto) das variações desses elementos nos diferentes espaços terrestres, um dado tomado isoladamente pode tanto refletir um valor médio quanto um desvio em relação a essa média, o que justifica a necessidade de decomposição cronológica e representação contínua e concomitante dos elementos climáticos para a real compreensão do clima.

No contexto do conceito de clima como um sistema, para Monteiro $(1978$, p.61) "O espaço revela as partes e a estrutura do sistema, enquanto as sequências temporais dos elementos ativos pretende revelar o processo" (neste caso, dinâmica ou ritmo do sistema climático). O "espaço", neste caso, foi identificado com os controles de superfície (naturais e urbanos) e, integrado aos "tipos de tempo", compõe a "estrutura". Os "processos" são denunciados pelas variações dos elementos climáticos em cada porção do espaço ao longo 
do tempo cronológico e resulta na totalidade de eventos e fenômenos climáticos conhecidos (inversões térmicas, "ilhas de calor", isotermia etc.). A síntese, identificada com a organização do clima, resulta da relação entre "estrutura" e "processo".

Referir-se à cidade como objeto capaz de produzir modificações no comportamento dos elementos atmosféricos, significa dizer, também, que ela é capaz de modificar o ritmo de comportamento desses elementos. Isso não significa, necessariamente, que qualquer cidade possua condições de impor transformações ao ambiente a ponto de imprimir-lhe um ritmo próprio.

O ritmo climático nas áreas urbanas, por exemplo, é diferente do ritmo climático em unidades de climas locais ou regionais, fortemente atreladas, respectivamente, à sucessão dos tipos de tempo e à dinâmica das massas de ar. Caso assim fosse, bastaria a compreensão das características do clima local ou regional para compreender todo o sistema climático. A diversidade de espaços numa cidade (ou mesmo da superfície terrestre, independente da escala) se reveste de características próprias e, portanto, de climas particulares (microclimas, topoclimas, mesoclimas etc.).

No tocante à imposição de um ritmo climático urbano ao clima local das cidades grandes e metrópoles, embora previsto por Monteiro (1975) ao referir-se à capacidade de "autorregulação" do sistema climático na definição de clima urbano, poucos foram os trabalhos que demonstraram isso experimentalmente.

Entre os trabalhos nessa linha de pesquisa destacam-se os de Azevedo (2001a; 2001b). O autor encontrou evidências de ritmo climático influenciado pela dinâmica urbana na cidade de São Paulo ao comparar trechos temporalmente diferenciados de série de dados meteorológicos. Os dois segmentos temporais de dados meteorológicos de períodos diferenciados, o primeiro entre 1933 a 1949 e o segundo, mais recente, com dados da década de 1990-2000, o autor verifica para o segmento temporal mais recente a ocorrência de picos máximos às quartas-feiras de temperatura do ar e do solo, mínimas de umidade relativa, mínimas de pressão atmosférica, máximos médios de velocidade dos ventos e máximos de precipitação.

Ao que tudo indica esse aspecto na variação temporal dos elementos do clima não ocorre por acaso, haja vista a não verificação desse comportamento na série temporal de 1933-1949. O autor observa, também, que esse dia da semana é o menos sujeito a "emendas" de feriados e, portanto, o dia mais propício à produção de calor de origem antropogênica associado à dinâmica e funções urbanas.

\section{CARACTERIZAÇÃO DA ÁREA DE ESTUDO}

Dentre as localidades incluídas nesta pesquisa (Figura 1) inclui-se o município de Belo Horizonte

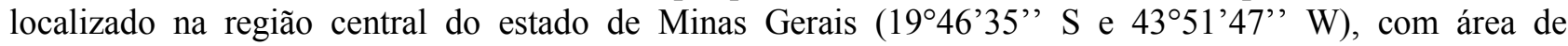
aproximadamente $331,4 \mathrm{~km}^{2}$. De acordo com dados do Instituto Brasileiro de Geografia e Estatística - IBGE (www.ibge.gov.br) a população estimada em 2015 é de 2.502.557 habitantes e densidade demográfica de $7.167 \mathrm{hab} / \mathrm{km}^{2}$. A Região Metropolitana de Belo Horizonte é constituída de 34 municípios sendo, atualmente, a terceira maior aglomeração urbana no país.

As altitudes variam entre 800-900 m e de acordo com Abreu e Barroso (2004), o município se encontra no contato entre dois principais conjuntos morfoestruturais, o Quadrilátero Ferrífero e a Depressão de Belo Horizonte. Situada no alto vale do rio das Velhas, integra o conjunto maior formado pela Bacia do Rio São Francisco.

O clima de Belo Horizonte é caracterizado pela existência de duas estações distintas, um período de seca no inverno e chuvoso no verão, com temperatura média anual de $21,1^{\circ} \mathrm{C}$ e total médio anual de chuvas de 1463,7 mm (DNMET, 1992). De acordo com Cavalcanti et al. (2009), a área onde se situa Belo Horizonte está inserida no interior da zona onde as linhas de instabilidades tropicais constituem o principal fator genético das chuvas nesses locais. A distribuição espacial da pluviosidade na região sudeste também é fortemente controlada pela atuação das frentes polares, disposição do relevo e influência da continentalidade.

$\mathrm{Na}$ região encontram-se as mais diversificadas fitofisionomias, resultantes da altitude e grande variedade de solos, sendo as mais representativas o campo sujo, campos de altitude e associações florestais de cerrado e mata atlântica, quase todas destruídas em função do crescimento urbano. 
Segundo Lobo (2007), atualmente, praticamente toda a área de Belo Horizonte está urbanizada, não havendo praticamente espaços para que ocorra expansão mobiliaria, favorecendo a verticalização dos bairros do município. A economia é caracterizada pela predominância do setor terciário $(80 \%$ da economia do município) com destaque para o comércio, prestação de serviços, setores de tecnologia de ponta, serviços financeiros, atividades imobiliárias e administração pública.

O município de Ibirité (2001'15" S e $40^{\circ} 03^{\prime} 52^{\prime}$ ' W) integra a Região Metropolitana de Belo Horizonte. A população estimada em 2015 é de 173.873 habitantes e a densidade demográfica é de 2.190,26 hab $/ \mathrm{km}^{2}$, ocupando área de $73 \mathrm{~km}^{2}$.

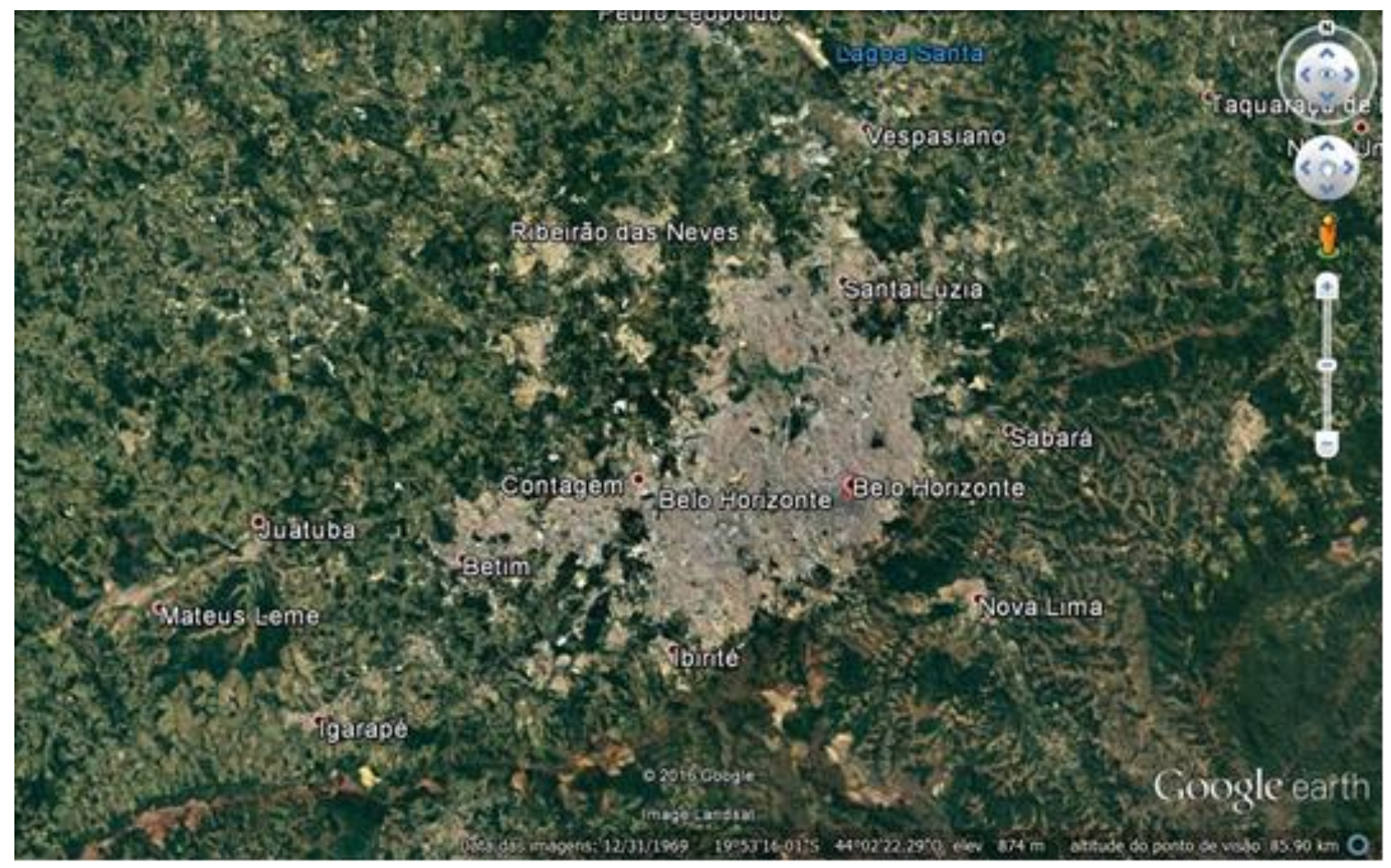

Figura 1: Localização da área de estudo. Destaque para Belo horizonte e os municípios vizinhos de Contagem e Ibirité (MG). Fonte: Google Earth.

O relevo do município apresenta no setor sul elevados desníveis topográficos e declividades elevadas $\left(>45^{\circ}\right)$, inserindo-se na bacia hidrográfica do rio Paraopeba. A temperatura média anual corresponde a $20,4^{\circ} \mathrm{C}$ e o total médio anual de chuvas é de $1424,4 \mathrm{~mm}$ (DNMET, 1992).

Atualmente a produção econômica do município está ligada ao setor de serviços. Na década de 1990 foi instalado um distrito industrial que abriga empresas de diversos ramos, desde a confecção de artigos para vestuário e fabricação de peças para veículos automotores até a fabricação de produtos alimentícios e bebidas.

Em relação à escala temporal abarcada pelos dados utilizados neste artigo, o número de habitantes para Belo Horizonte e Ibirité correspondente aos anos de 1960 e 2010, representa, respectivamente, valores aproximados de $683.908-2.375 .151$ habitantes e 3.952 - 158.954 habitantes. 


\section{RESULTADOS}

No decorrer do mês de outubro/novembro de 2012 verificaram-se valores elevados de temperatura do ar superiores a $30,0^{\circ} \mathrm{C}$, o que, em princípio, não se constitui fato incomum considerando a latitude de Belo Horizonte e as características da estação naquela ocasião. Houve, inclusive, aqueles que naquele dado momento se apressaram em afirmar que se tratava de valores nunca antes registrados.

Em matéria de Ramon Guerra do site de notícias R7-MG datada de 31/10/2012 ${ }^{1}$ consta o seguinte:

Belo Horizonte registra temperatura mais alta da história da cidade. Segundo INMET, termômetros marcaram $37,1^{\circ} \mathrm{C}$ nesta quarta-feira (31) (...) Os belo-horizontinos que gostam de calor puderam "comemorar" mais um recorde na tarde desta quarta-feira (31). Isso porque, segundo o INMET (Instituto Nacional de Meteorologia), foi registrada a temperatura mais alta de todos os tempos da capital mineira, com incríveis $37,1^{\circ} \mathrm{C}$, registrados em uma estação de medição localizada no bairro Santo Agostinho, na região centro-sul de Belo Horizonte (...) Conforme o meteorologista Lisandro Gemiacki, a onda de calor é resultado de uma massa de ar quente que está sobre a região Sudeste do Brasil, que fez com que outras cidades do Estado marcassem temperaturas acima da casa dos $40^{\circ} \mathrm{C}$. A marca surpreendeu os meteorologistas do próprio instituto, que, na manhã desta quarta-feira (31), haviam previsto temperatura máxima de $34^{\circ} \mathrm{C}$ para a capital mineira.

O mesmo se repetiu em 2015 conforme matéria divulgada pelo site http://www.em.com.br/ em 16/10/2015 ("Belo Horizonte tem o dia mais quente da história") de autoria de João Henrique do Vale e Guilherme Paranaíba:

A capital mineira atingiu a maior temperatura já registrada na cidade desde 1910. Os termômetros chegaram, por volta das $14 \mathrm{~h} 15$, a $37,4^{\circ} \mathrm{C}$ na estação de medição da Pampulha. $\mathrm{O}$ valor superou a máxima histórica de $37,1^{\circ} \mathrm{C}$, registrada em 30 de outubro de 2012 . A umidade relativa do ar está em torno de $12 \%$, o que é considerado estado de alerta pela Organização Mundial da Saúde (OMS). Quando o índice fica abaixo de $30 \%$ já é prejudicial à saúde

Entretanto, um exame da série temporal de dados meteorológicos do INMET (www.inmet.gov.br) no período de 1961-2015 (Tabela 1) revela que valores dessa magnitude já foram verificados em diferentes momentos. Em 1987, por exemplo, no dia $19 / 10$ foi registrado $36,9^{\circ} \mathrm{C}$, ou seja, $0,2^{\circ} \mathrm{C}$ inferior ao dado de 2012 e 2015 de $37,1^{\circ} \mathrm{C}$. Essa diferença, além de insignificante em termos de impacto pode, inclusive, constar da margem de erro instrumental.

Tabela 1: Extremos de temperatura verificados em Belo Horizonte - MG a partir do ano de 1961.

\begin{tabular}{lrlr}
\hline Data & Temperatura & Data & Temperatura \\
\hline $13 / 10 / 1963$ & $35,5^{\circ} \mathrm{C}$ & $25 / 01 / 2006$ & $35,1^{\circ} \mathrm{C}$ \\
$04 / 09 / 1975$ & $35,0^{\circ} \mathrm{C}$ & $26 / 01 / 2006$ & $35,4^{\circ} \mathrm{C}$ \\
$19 / 10 / 1987$ & $36,9^{\circ} \mathrm{C}$ & $24 / 09 / 2007$ & $36,1^{\circ} \mathrm{C}$ \\
$30 / 01 / 1988$ & $35,4^{\circ} \mathrm{C}$ & $17 / 10 / 2007$ & $36,2^{\circ} \mathrm{C}$ \\
$17 / 01 / 1995$ & $35,1^{\circ} \mathrm{C}$ & $05 / 10 / 2008$ & $35,2^{\circ} \mathrm{C}$ \\
$10 / 09 / 1997$ & $35,7^{\circ} \mathrm{C}$ & $27 / 10 / 2008$ & $35,1^{\circ} \mathrm{C}$ \\
$05 / 02 / 1998$ & $35,2^{\circ} \mathrm{C}$ & $31 / 07 / 2012$ & $37,1^{\circ} \mathrm{C}$ \\
$21 / 10 / 2003$ & $35,1^{\circ} \mathrm{C}$ & $22 / 10 / 2015$ & $37,1^{\circ} \mathrm{C}$ \\
\hline
\end{tabular}

Fonte: www.inmet.gov.br (dados da estação convencional sede do INMET $5^{\circ}$ DISME, Avenida do Contorno, 8159, Belo Horizonte-MG).

\footnotetext{
${ }^{1}<$ http://noticias.r7.com/minas-gerais/noticias/belo-horizonte-registra-temperatura-mais-alta-da-historia-da-cidade20121031.html> Acesso: 07/11/2012.

${ }^{2}<$ http://www.em.com.br/app/noticia/gerais/2015/10/16/interna_gerais,698574/belo-horizonte-registra-sua-maiortemperatura-da-historia.shtml> Acesso: 13/06/2016. 
Diante do exposto, a fim de explicar a situação apresentada, foram formuladas as seguintes hipóteses: (1) tratar-se-ia, antes de tudo, de um evento natural, ligado à dinâmica de sucessão e encadeamento temporal de massas de ar de origem tropicais, desdobradas em tipos de tempo locais, de ocorrência típica na latitude de Belo Horizonte durante a estação de primavera; (2) influencia crescente do clima urbano, decorrente do crescimento da população e das estruturas e funções urbanas e, portanto, da multiplicação das fontes de produção de calor de origem antropogênica; (3) acoplamento de ambos os processos: evento natural conjugada à influência do clima urbano; (4) tendência persistente de longo prazo de aumento das temperaturas associado às supostas mudanças climáticas globais, cujo imperativo repousa sobre o aumento contínuo e persistente das temperaturas associadas ao aumento na quantidade de gás carbônico atmosférico em função das atividades humanas.

Considerou-se, também, (5) que a relativa escassez de dados climáticos (espacial e temporal) oriundos de estações meteorológicas em superfície não permitiu suficiente acumulo de dados para registro de outros eventos dessa natureza e magnitude em tempos passados, bem como (6) permanece válido o questionamento sobre a validade do dado quantitativo relativo à temperatura máxima absoluta como indicador de tendência de variação temporal da temperatura do ar, uma vez que a sua natureza indica maior dispersão temporal em relação às temperaturas mínimas quando comparado a medidas de tendência central (valores médios) o que diminui sua eficácia como indicador de tendências e correlações.

A hipótese 04 foi descartada uma vez que não há verificação experimental desse processo através da análise de séries temporais de dados meteorológicos disponíveis, cujo intervalo temporal pouco superior a 100 anos em algumas poucas estações distribuídas pelo país é insuficiente para captar informações dessa natureza. Além do mais, as temperaturas não aumentam desde 1998, com tendência ao declínio, inclusive, embora tenha experimentado desvio positivo no ano de 2015, devido à progressão do El Niño naquele ano. Pairando, portanto, apenas especulações fundadas em cenários (modelos gráficos e numéricos).

Nesse sentido, resta questionar sobre como a área urbana de Belo Horizonte, em conjunto com as características do sítio que lhe dá suporte, articula-se com a circulação atmosférica local e regional para produzir os valores de temperatura da magnitude daqueles verificados, expressas pelas hipóteses 01,02 e 03 . $\mathrm{Ou}$, dito de outra forma, verificar quanto daqueles valores registrados ao final do mês de outubro de $2012 \mathrm{e}$ 2015 (e em outros momentos, também) guarda relação com variáveis naturais (massas de ar, relevo etc.) e urbanas.

As modificações pelas quais passou o município de Belo Horizonte (ampliação da área urbana, redução das áreas verdes, aumento da população, da frota de veículos, do parque industrial, de comércio e prestação de serviços etc.) introduziram um número incontável de fontes de calor de origem antropogênica que, por sua vez, trouxe impactos diretos no ambiente e, consequentemente, no clima de Belo Horizonte.

De acordo com os dados apresentados na caracterização da área de estudo entre os anos de 1960 e 2010 o crescimento populacional foi superior a $300 \%$ em Belo Horizonte, acompanhado de incremento na área edificada a ponto de praticamente esgotar o estoque de terrenos vagos no município. De acordo com Euclydes e Fonseca (2013) apenas 12,6\% do território de Belo Horizonte constituem-se em áreas protegidas, fortemente concentradas no limite sul e sudeste do município acompanhando a Serra do Curral (Pq. Estadual da Serra do Rola Moça, Estação Ecológica do Cercadinho, Pq. Municipal das Mangabeiras e Pq. Estadual da Baleia).

Verificou-se, também, aumento da frota de veículos particulares: em 1986 Belo Horizonte contava com 400 mil, passando em 866.304 unidades em 2006 e alcançando aproximadamente 1,7 milhões em 2016, além da diversificação no setor de serviços, aquisição de máquinas e equipamentos eletromecânicos etc. A própria modificação da superfície (substituição de superfícies naturais por artificiais) altera as propriedades de albedo, absorção, armazenamento e condução de calor, mesmo se tratando de fontes passivas de radiação.

O reflexo dessas modificações pode ser visualizado nas tendências e correlações verificadas na série temporal de variação da temperatura do ar de Belo Horizonte em comparação à Ibirité. Nos dois casos, conforme Figuras 2 e 3, é patente o aumento natural de temperatura associado à fase de aquecimento do oceano Pacífico (ODP) que, de acordo com Molion (2005), teve início em 1977, antecedida pela fase fria iniciada por volta de 1945, perdurando até 1998. Ou seja, embora a dinâmica climática nessas localidades guarde estreita relação com fenômenos de escala superior é ao nível local e microclimático que se busca explicações para os diferentes resultados.

O município de Ibirité apresentou o maior grau de correlação no que diz respeito à temperatura máxima $\left(R^{2} 0,495\right)$, ao contrário de Belo Horizonte $\left(R^{2} 0,1257\right)$ que registrou fraca tendência na variação 
desse elemento (Figuras 2 e 3). A partir de meados da década de 1970, Ibirité experimentou aumento gradual nas máximas locais. Essa tendência, de certa forma, acompanhou o processo de modificação da paisagem natural, incluindo a urbanização, pelo qual passou o município na referida década, embora tenha sido detectada fraca tendência e correlação para Ibirité em relação às mínimas (Figura 3).

Em relação às temperaturas mínimas, o coeficiente de determinação para Belo Horizonte foi relativamente alto $\left(R^{2} 0,5658\right)$ comparado à Ibirité $\left(R^{2} 0,081\right)$. Apesar do valor inexpressivo do coeficiente de determinação em Ibirité, deve-se considerar que no caso de Belo Horizonte, cujo efeito dessa maior transformação nas características de uso da terra, traduzido pelo valor do coeficiente de determinação, pode ser interpretado enquanto indício e/ou evidência de imposição de um ritmo climático local associado a essas transformações no âmbito da paisagem.

O coeficiente de determinação $\left(\mathrm{R}^{2}\right)$ das temperaturas médias mínimas em Belo Horizonte, em princípio, não se mostra significativo $\left(\mathrm{R}^{2}=0,374\right)$. Entretanto, quando comparado aos dados de Ibirité notase que de fato houve alteração expressiva em Belo Horizonte.

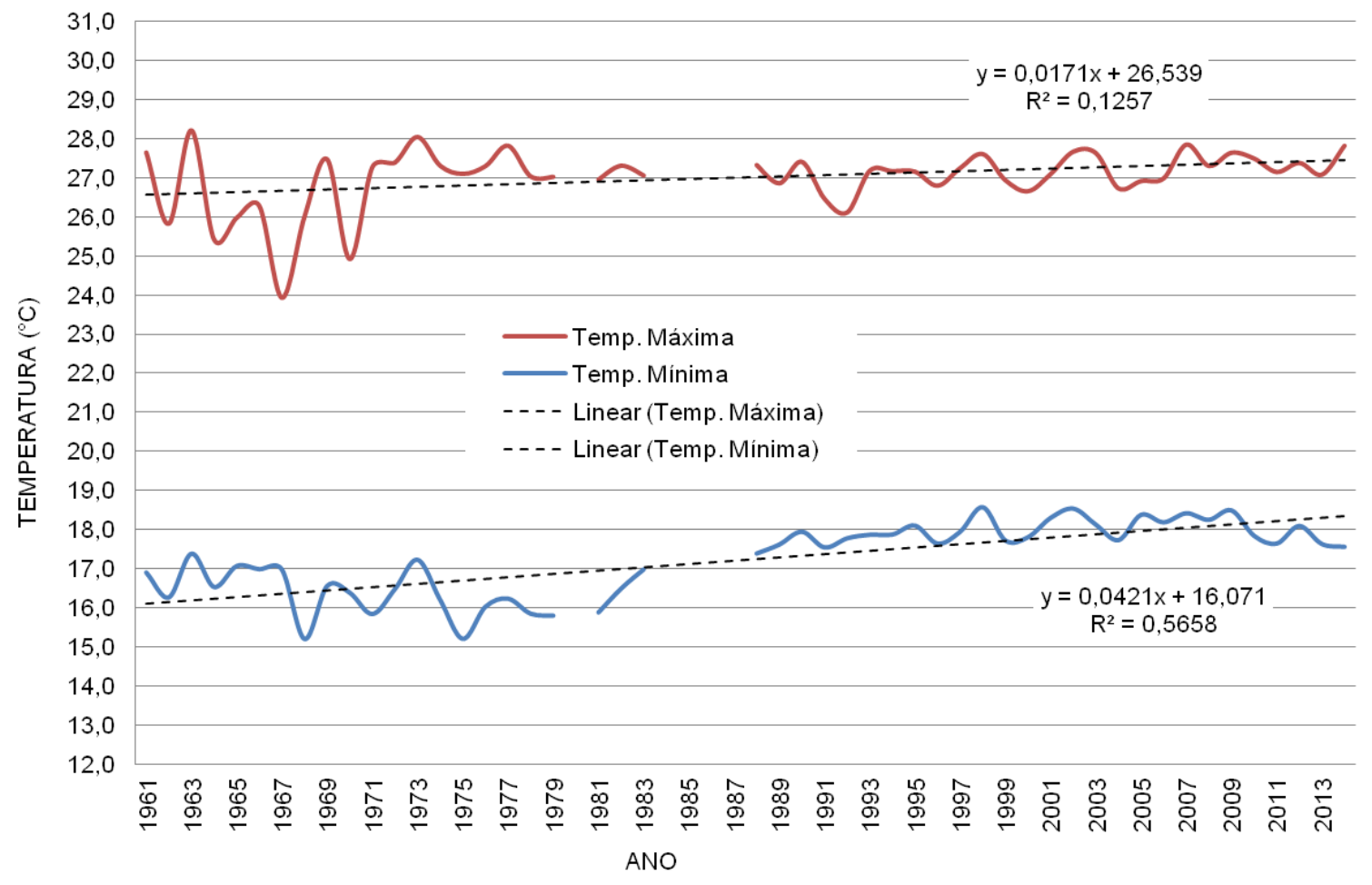

Figura 2: Tendências e correlações nas variações da temperatura média máxima e mínima em Belo Horizonte - MG (1961 - 2014). Fonte: www.inmet.gov.br. 


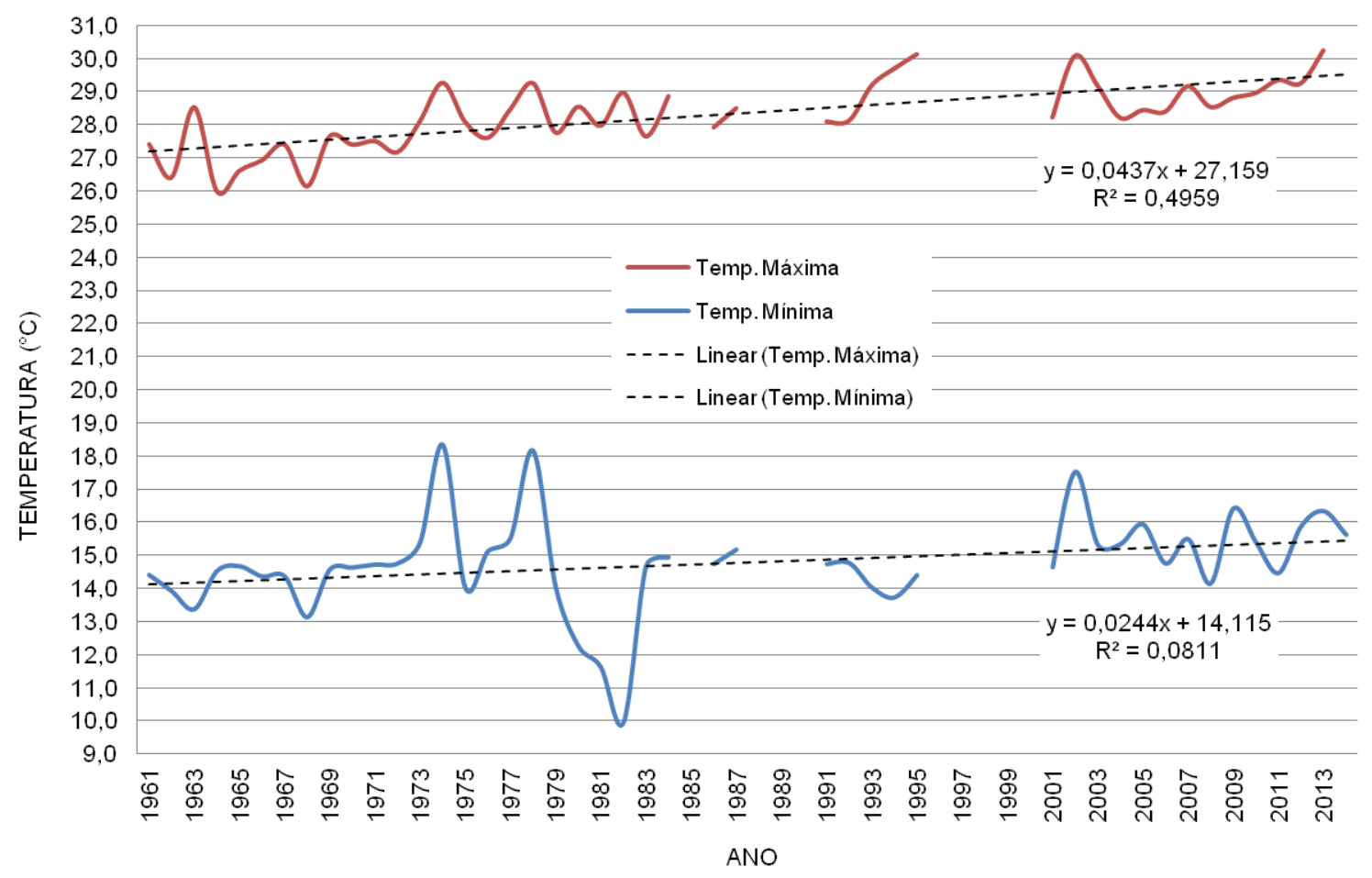

Figura 3: Tendências e correlações nas variações da temperatura média máxima e mínima em Ibirité - MG (1961 - 2014). Fonte: www.inmet.gov.br.

Em relação aos dados de temperatura média máxima (Figura 4), observa-se um aumento progressivo, que se inicia na quarta-feira em direção à sexta-feira na sequência de 2001-2010, disposição não verificada na sequência de 1961-1970. Especula-se que o padrão identificado no gráfico é resultado cumulativo do movimento interno da própria cidade, isto é, do calor produzido pelas atividades antrópicas. As estruturas presentes na cidade demoram determinado tempo para armazenar e dissipar o calor, acumulado no decorrer da semana.

Quando se comparam as duas sequências temporais, nos dados da média semanal de temperatura mínima (Figura 4) pode-se verificar a não ocorrência de "picos" destacados ao longo da semana na sequência supostamente menos influenciada pelas alterações no uso da terra (1961-1970), ao contrário da sequência mais recente de 2001-2010 em Belo Horizonte, embora menos destacado em relação às máximas, culminando de forma progressiva com valores mais elevados às quartas-feiras.

Nos gráficos de variação semanal da temperatura em Belo Horizonte (Figura 4) é nítida a ruptura desse padrão no final de semana (sábado e domingo), inclusive na sequência mais antiga, provavelmente em decorrência da diminuição do fluxo de veículos e pessoas pelas ruas e dinâmica do comércio, serviços e atividade industrial.

Outro fator a ser considerado, e que provavelmente está embutido no padrão de variação encontrado, é o deslocamento de parte da população após o fim do período de trabalho para áreas de lazer, como sítios e fazendas, situadas fora da cidade.

A julgar pelo valor do coeficiente de determinação da temperatura média máxima na Figura $4\left(\mathrm{R}^{2}=\right.$ 0,7061) na sequência de 2001-2010, pode-se especular ao redor de um aumento cumulativo de calor durante a semana decorrente da concentração de atividades urbanas. 

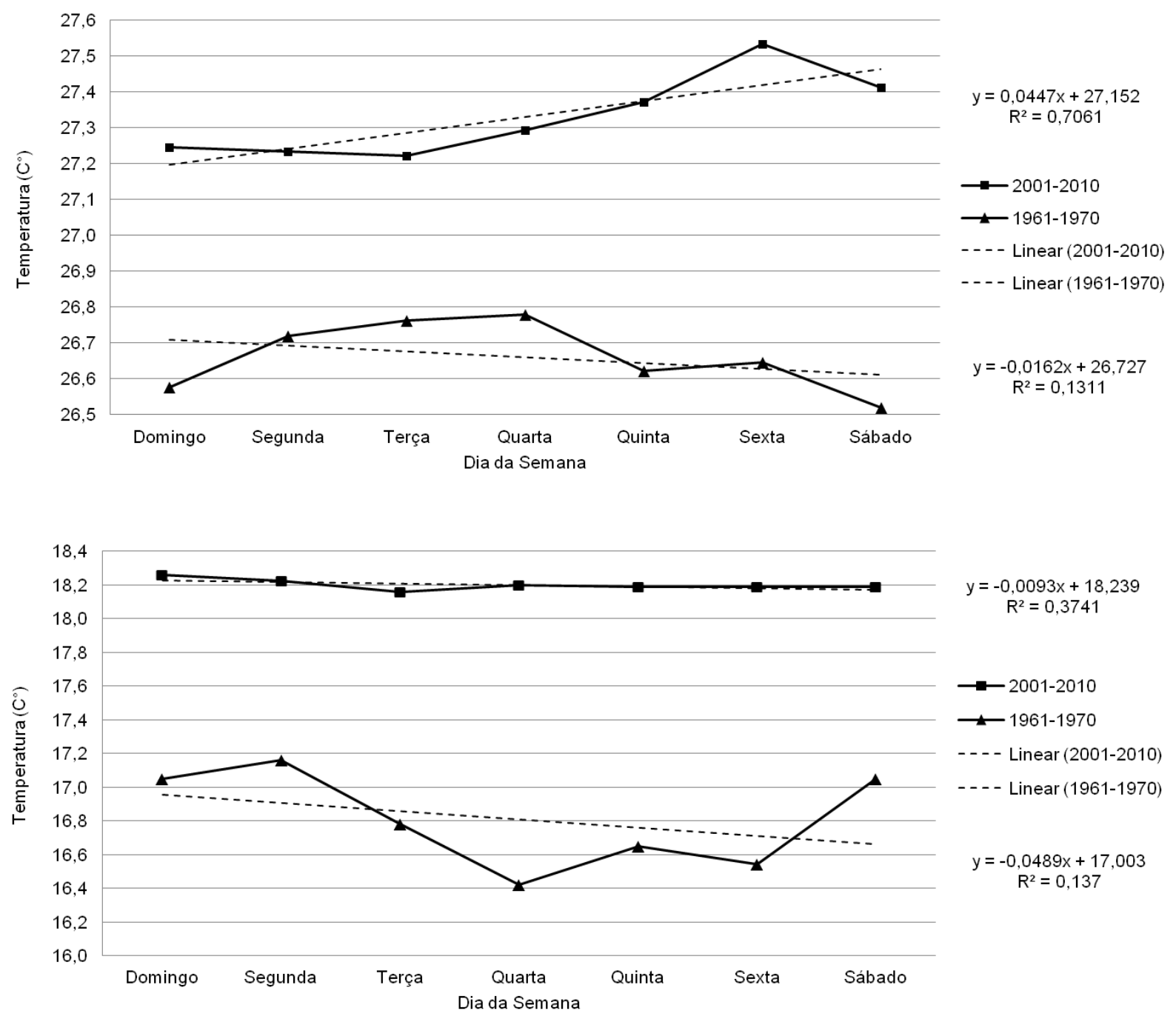

Figura 4: Variação semanal da temperatura média máxima (acima) e mínima (abaixo) em Belo HorizonteMG (1961-1970 e 2001-2010). Fonte: www.inmet.gov.br.

Nos gráficos relativos à variação semanal da temperatura em Ibirité (Figura 5) foi constatado, assim como em Belo Horizonte, aumento natural das temperaturas máximas nas sequências de 2001-2010 associado à fase quente da Oscilação Decadal do Pacífico (ODP) e a atividade solar, embora esse efeito não apareça de forma destacada na variação das temperaturas mínimas. Entretanto, não foi revelada mudança significativa nos padrões de temperatura durante a semana, provavelmente pelo fato desse município não ter experimentado mudanças significativas em termos de uso da terra e funções urbanas com a mesma intensidade que Belo Horizonte. Tanto os baixos valores do coeficiente de determinação $\left(\mathrm{R}^{2}\right)$ quando a falta de continuidade temporal em progressão nas curvas representativas da variação das temperaturas máximas e mínimas evidencia esse fato.

Os valores do coeficiente de determinação em ambas as cidades, tanto para a temperatura máxima quanto para a temperatura mínima se mostraram baixos, indicando que as variações semanais da temperatura nos municípios não guardam relação evidente com as mudanças introduzidas ao longo do tempo.

Outro importante fator a ser ressaltado é a localização das estações em cada município: a estação meteorológica de Ibirité se encontra num contexto distinto daquela de Belo Horizonte, em área periurbana, limítrofe à unidade de conservação do Rola Moça. Já a estação meteorológica de Belo Horizonte encontra-se exatamente entre duas importantes e movimentadas avenidas na região central da cidade, o que permite inferir maior comprometimento com condições ambientais urbanas. 

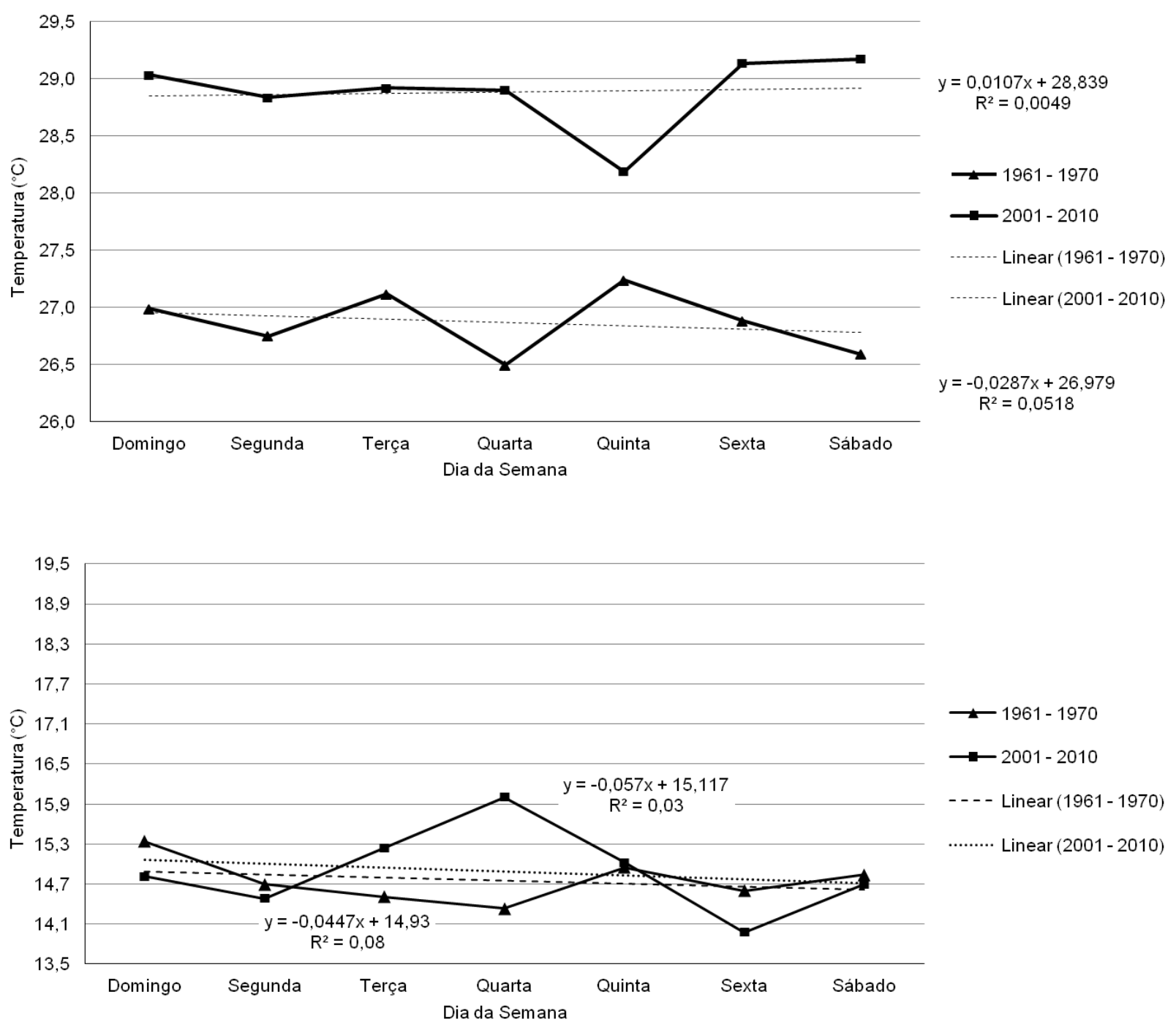

Figura 5: Variação semanal da temperatura média máxima (acima) e mínima (abaixo) em Ibirité-MG (19611970 e 2001-2010). Fonte: www.inmet.gov.br.

Passando para outra escala de análise, as variações momentâneas (horárias) e simultâneas de temperatura do ar entre Belo Horizonte (regional Barreiro, sul de Belo Horizonte) e Contagem (área urbana próxima ao distrito industrial), tomadas ao nível de espaços micro e topoclimáticos, revestiram-se de dois aspectos básicos: (1) as componentes ligadas à estrutura e dinâmica urbanas não se constituíram no principal fator a influenciar nas variações detectadas dividindo esse papel com componentes ligados ao relevo e condições atmosféricas específicas; (2) o montante quantitativo dos valores de temperatura situou-se, na maior parte dos casos, em patamar inferior a $2,0^{\circ} \mathrm{C}$ quando comparados pontos com características distintas de uso e ocupação, caso da área urbana na regional Barreiro, sul de Belo Horizonte, próximo a áreas de conservação e o posto situado em área densamente urbanizada do município de Contagem (Figura 6). 


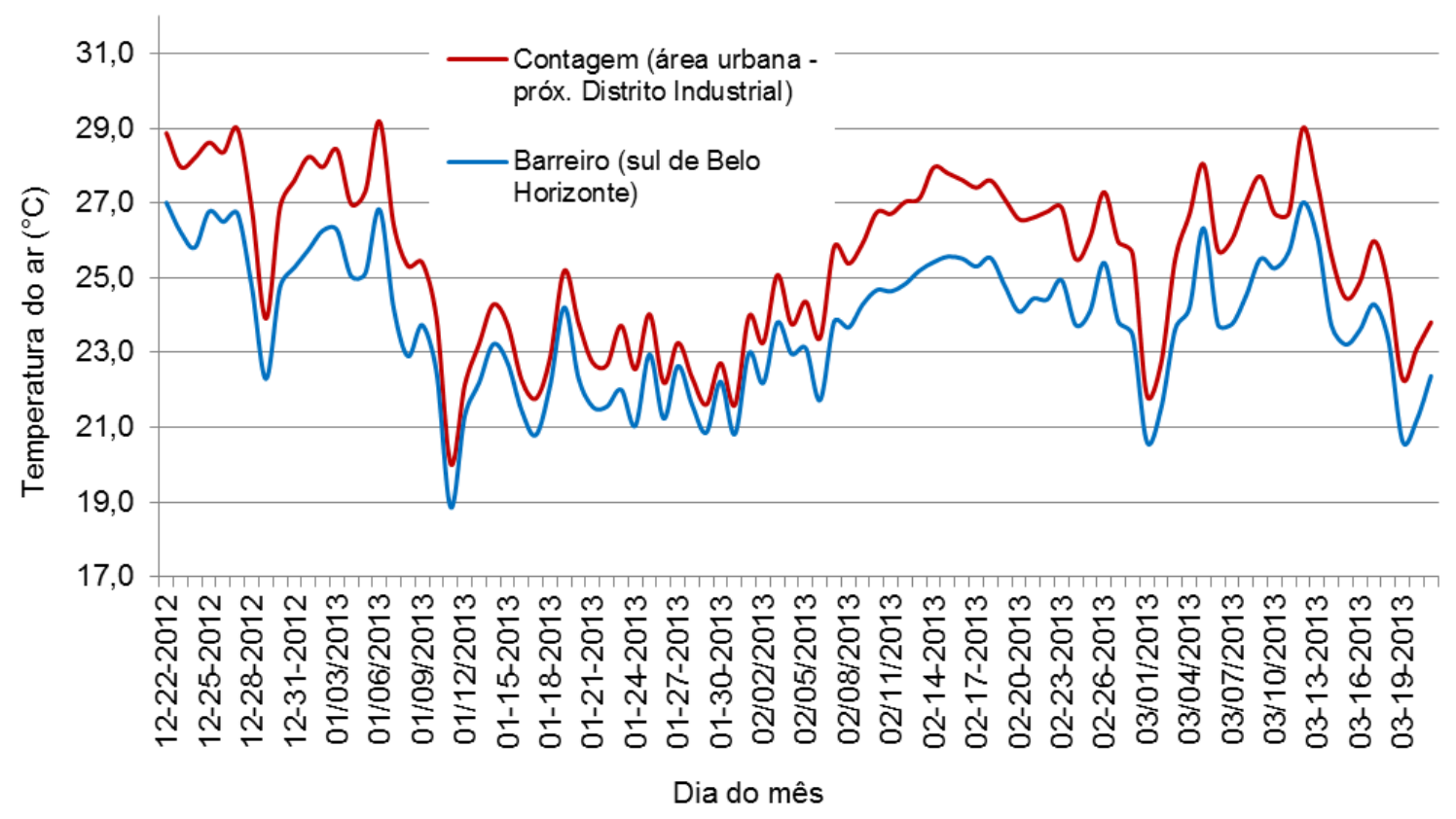

Figura 6: Variação da temperatura média diária em na área urbana de Belo Horizonte/regional Barreiro e em Contagem-MG (22/12/2012 - 21/03/2013). Fonte: dados oriundos de trab. campo - Elab./autores.

As condições atmosféricas durante o período de registro foram caracterizadas pela alternância entre sistemas de alta e baixa pressão: inicialmente essas condições foram orientadas pela ação do anticiclone Subtropical do Atlântico Sul (ASAS) até o dia 10/01/2013 (marcado pelos maiores contrastes de temperatura entre os dois postos), em seguida pela ação conjunta do Anticiclone Subpolar do Atlântico Sul (APA), instabilidade associadas à atuação da Frente Polar Atlântica (FPA) e Linhas de Instabilidade (LI) entre 11/01 e 07/02/2013, momento em que as variações de temperatura tenderam a se atenuar, decorrente da elevada nebulosidade e interceptação da radiação solar. Retorno da ação do ASAS (com a participação da FPA em curtos períodos) até o final da sequência, predominando novamente condições de elevado contraste de temperatura. Durante todo esse período verificou-se a participação horária e esporádica de núcleos locais de nuvens convectivas acompanhada de chuvas intensas de curta duração, típicas dessa estação.

O posto instalado na área urbana central de Contagem, em condições de tempo estável quente, apresentou valores mais elevados de temperatura do ar com frequência média de $88 \%$ em relação aos demais postos. Situado em cota altimétrica de $925 \mathrm{~m}$, este posto apresenta elevada ocupação urbana e sede do maior polo industrial do estado de Minas Gerais. Os postos que apresentaram os menores valores de temperatura estão localizados em pequenos núcleos urbanos (Nova Lima e Betim) ou em cota altimétrica igual ou superior a $1000 \mathrm{~m}$ (bairros Sion e Barreiro em Belo Horizonte), cujas diferenças horárias de temperatura em relação ao posto de Contagem atingiram valores momentâneos horários superiores a $4,0^{\circ} \mathrm{C}$ em diversas ocasiões.

Em relação ao posto do bairro Barreiro, cujos valores médios diários de temperatura foram superados em sua totalidade pelo posto de Contagem, os valores iguais ou superiores a $2,0^{\circ} \mathrm{C}$ ocorreram em 33 ocasiões dentre 90 dias, ou seja, $36,7 \%$. A maior diferença média anotada para esses dois postos foi de $2,5^{\circ} \mathrm{C}$.

No tocante aos valores horários em relação aos máximos diários absolutos, essas diferenças alcançaram as frequências de $4,4 \%$ para valores $\geq 4,0^{\circ} \mathrm{C}$ ( 04 ocorrências de um total de 90 situações), $12,2 \%$ para a classe $\geq 3,0^{\circ} \mathrm{C}$ e $<4,0^{\circ} \mathrm{C}$ ( 11 ocorrências), $31,1 \%$ para a classe $\geq 2,0^{\circ} \mathrm{C}$ e $<3,0^{\circ} \mathrm{C}$ ( 28 ocorrências) e para a classe de valores com diferenças inferiores a $2,0^{\circ} \mathrm{C}$ o percentual foi de $45,5 \%$ das situações. Em 05 situações o posto do Barreiro foi mais quente do que o posto de Contagem $(5,5 \%)$ e em apenas uma única ocasião não houve registro de diferenças, ou seja, os valores se igualaram.

Para os valores mínimos absolutos não houve diferença superior a $3,0^{\circ} \mathrm{C}$. Para a classe $\geq 2,0^{\circ} \mathrm{C}$ e $<3,0^{\circ} \mathrm{C}$, com 22 ocorrências ou $24,4 \%$ das ocasiões. Todas as demais ocorrências $(75,6 \%)$ constituem-se de valores inferiores a $2,0^{\circ} \mathrm{C}$. A classe com valor $\geq 1,0^{\circ} \mathrm{C}$ perfaz $17,8 \%$ com 16 ocorrências. 
As diferenças de temperatura foram desencadeadas por dois fatores básicos favorecendo menores valores de temperatura no posto do Barreiro: maior valor de altitude no posto Barreiro (1000 m contra 925 de Contagem) e presença massiva de vegetação decorrente da proximidade em relação à unidade de conservação da Serra do Rola Moça no extremo sul de Belo Horizonte em conjunto com o Pq. Estadual da Baleia, o Pq. Municipal das Mangabeiras e a estação Ecológica do Cercadinho.

A proximidade em relação a superfícies florestais de grande dimensão e sua zona de influência (ainda não devidamente avaliada) sugere modificações em favor de um menor saldo de energia disponível para condução (os materiais orgânicos, em geral, são péssimos condutores e armazenadores de calor) e transporte advectivo pelo ar. A interceptação da radiação solar pelo dossel florestal e utilização de parte do saldo energético nos processos metabólicos da planta e no mecanismo de evapotranspiração, convertem parte do calor sensível disponível para aquecer o ar (e todo o ambiente) em calor latente.

Em relação ao efeito orográfico (os valores de altitude na serra do Rola Moça, situada no divisor de águas entre as bacias do São Francisco e o Rio Doce, são superiores a 1500 m), pode-se argumentar a respeito do resfriamento em função da expansão adiabática do ar e drenagem de ar frio oriundo do alto da serra no período noturno (vento catabático) em direção a áreas deprimidas, verificadas em diversos contextos de trabalhos diferenciados.

\section{CONSIDERAÇÕES FINAIS}

A análise dos dados trouxe evidências da participação humana como fator de variação da temperatura do ar. O que não é novidade, haja vista a imensa quantidade de pesquisas ao redor dessa temática. Entretanto, essa influência não é decisiva e, em grande parte das situações, sequer mostra-se evidente, mesmo na análise dos dados de campo em nível micro e topoclimático onde a ação antrópica é mais evidente, cabendo alguns apontamentos:

(1) Valores extremos de temperatura são recorrentes de qualquer realidade local e constam de qualquer série temporal de dados meteorológicos, não sendo, portanto, privilégio do atual momento. Valores positivos de temperatura superiores a $35,0^{\circ} \mathrm{C}$ são experimentados rotineiramente por grande parte da população brasileira em diferentes momentos e regiões do Brasil ao longo do ano;

(2) Tais eventos estão embutidos em contexto climático maior, ou seja, podem fazer parte de ciclos ou fases de fenômenos como o El Niño, a fase quente da Oscilação Decadal do Pacífico e máximos de atividade solar, que podem atuar em teleconexão, como ocorreu no final dos anos 1990, reforçando períodos mais quentes como aquele de 1998 e, mais recentemente, em 2015 em função de evento de El Niño em progressão naquele ano;

(3) A evolução e encadeamento dos valores de temperatura ao longo de um dado período, muitas vezes, coincidem com "picos" horários de curtíssima duração, não se mantendo por horas seguidas. O próprio descompasso na evolução horária da temperatura entre diferentes pontos numa mesma cidade produzem essas diferenças;

(4) A pouca expressão quantitativa de classes com diferenças de temperaturas elevadas se deve muito mais a capacidade de autorregulação do clima, através da sucessão dos tipos de tempo, envolvendo o transporte do excedente energético de calor para áreas deficitárias pelo movimento advectivo de ar, do que propriamente resultado de intervenção humana.

(5) A participação crescente das fontes de calor de origem antropogênica e desenvolvimento do clima urbano em Belo Horizonte também devem ser considerados;

Não se pode perder de vista o contexto no qual estão inseridas essas modificações no quadro ambiental. Em regiões de clima tropical, onde existe excedente de calor praticamente durante o ano inteiro, fatores que reforçam essa condição contribuem para reforçar negativamente o quadro de impactos. Dito isso, antes de imitir declarações a respeito, caberia identificar o impacto, quantificar, explicar e definir a dimensão do evento ocorrido.

A ação antrópica pode e deveria ser mais efetiva, não apenas no sentido de produzir impactos negativos, mas através de ordenamento espacial adequado e inclusão de técnicas de construção civil adaptadas às condições dos trópicos, a fim de favorecer a dissipação de calor. 


\section{REFERÊNCIAS}

ABREU, M. L., BARROSO, T. P. Caracterização climática dos ventos associados a eventos de precipitação extrema em Belo Horizonte - MG. Caderno de Geografia, Belo Horizonte, v. 14, n. 23, p. 135-152, 2004.

AZEVEDO, T. R. Derivação antrópica do clima na Região Metropolitana de São Paulo abordada como função do ritmo semanal das atividades humanas. Tese (Doutorado). Departamento de Geografia Faculdade de Filosofia, Letras e Ciências Humanas - Universidade de São Paulo. 2001a.

AZEVEDO, T. R; TARIFA, J. R. O ritmo semanal das atividades humanas e o clima na Região Metropolitana de São Paulo. Textos do Laboratório de Climatologia e Biogeografia - Departamento de Geografia / FFLCH / USP - Série TA - Texto 008. p.1-17. 2001 b.

CAVALCANTI, I.F.A.; FERREIRA, N.J.; SILVA, M.G.A.J.; SILVA DIAS, M.A.F. Tempo e clima do Brasil. 1.ed. São Paulo: Oficina de Textos, 2009. 464p.

DNMET. Departamento Nacional de Meteorologia. Normais Climatológicas (1961- 1990). Brasília-DF, 1992.

EUCLYDES, A. C. P; FONSECA, C. O. Áreas protegidas em Belo Horizonte (MG): levantamento e reflexões. In: VI SAPIS: Seminário Brasileiro sobre Áreas Protegidas e Inclusão Social, (15-20/09/2013), 2013, Belo Horizonte. Anais... IGC/UFMG, 2013.

JARDIM, C. H. Proposta de síntese climática a partir do comportamento térmico e higrométrico do ar em áreas urbanas. Tese (Doutorado) - Departamento de Geografia - Instituto de Geociências Universidade Estadual de Campinas, Campinas, 2007.

LOBO, C; GARCIA, R. A. Dinâmica demográfica urbana: crescimento populacional e saldo migratório das Áreas de Ponderação de Belo Horizonte. In: V Encontro Nacional sobre Migrações, 2007. Anais... Campinas/SP: Editora da ABEP, 2007.

MOLION, L.C.B. Aquecimento Global. El Niños, Manchas Solares, Vulcões e Oscilação Decadal do Pacífico. Climanálise, ano 03, n.01, 2005.

MONTEIRO, C. A. F. Análise rítmica em climatologia. Problemas da atualidade climática em São Paulo e achegas para um programa de trabalho. Climatologia, São Paulo, n.01, p.1-21, 1971.

MONTEIRO, C. A. F. Teoria e Cima Urbano. Tese (Livre Docência) - Faculdade de Filosofia, Letras e Ciências Humanas, Universidade de São Paulo, São Paulo, 1975.

MONTEIRO, C. A. F. Derivações antropogênicas dos geossistemas terrestres no Brasil e alterações climáticas: perspectivas urbanas e agrárias ao problema da elaboração de modelos de avaliação. In: I SIMPÓSIO A COMUNIDADE VEGETAL COMO UNIDADE BIOLÓGICA, TURÍSTICA E ECONÔMICA, 1978, São Paulo. Anais... São Paulo: Academia de Ciências do Estado de São Paulo, 1978 (Publicação ACIESP n.15). p. 43-76.

SORRE, M. Objeto e método da climatologia. In: Traité de Climatologie Biologique et Médicale. Tradução de José Bueno Conti Paris: M. Piery Masson et Cie Éditurs, 1934. Vol. 1, p.1-9. Original em francês. 